\title{
Association between alpha-thalassaemia trait, Plasmodium falciparum asexual parasites and gametocyte carriage in a malaria endemic area in Southern Ghana
}

Helena Lamptey ${ }^{1 *}$ (D, Michael Fokuo Ofori ${ }^{1}$, Bright Adu ${ }^{1}$, Kwadwo Asamoah Kusi ${ }^{1}$, Emmanuel Kakra Dickson ${ }^{1}$, Isabella Quakyi ${ }^{2}$ and Michael Alifrangis ${ }^{3,4}$

\begin{abstract}
Objective: The alpha-thalassaemia trait has been associated with protection against severe malaria but its role in Plasmodium falciparum asexual parasite and gametocyte carriage remains unclear. This study examined association between prevalence of a-thalassaemia and P. falciparum asexual stage parasitaemia and gametocytaemia in children, pregnant women and adults, which was part of a bigger study that investigated some key factors that influence gametocyte carriage.

Results: Overall prevalence of heterozygous a-thalassaemia trait among all the groups was 39.0\%, while 8.2\% were homozygous alpha thalassaemia. Asexual parasite prevalence was significantly higher in children $(P=0.008) \mathrm{com}$ pared to adults and pregnant women. Of the asexual P. falciparum positive individuals, gametocyte prevalence was $38.5 \%(15 / 39)$ in children, $29.7 \%(11 / 37)$ in pregnant women and 17.4\% (4/23) in adults. Heterozygous a-thalassaemic children were less likely to harbour asexual parasites, compared with normal and those deficient $(\mathrm{OR}=0.52 ; 95 \% \mathrm{Cl}$ $0.28-0.97 ; P=0.037)$ under the dominant model. These heterozygous children were also associated with reduced risk of parasitaemia compared to heterozygous adults and pregnant women. Children with heterozygous a-thalassaemia trait had reduced risk of asexual parasite carriage. There was however, no association between a-thalassaemia trait and risk of gametocyte carriage.
\end{abstract}

Keywords: Plasmodium falciparum, Submicroscopic parasites, Alpha-thalassaemia, Gametocyte carriage

\section{Introduction}

Certain genetic blood disorders such as the thalassaemia's $(\alpha, \beta)$ and sickle cell anaemia have been shown to influence malaria pathogenesis [1-3]. Heterozygous $\alpha$-thalassaemia have been shown to confer protection against severe malaria [4], however, there is limited data on its effect on asymptomatic parasite carriage [5, 6]. Some studies have shown that certain genetic traits like sickle cell that protect against severe malaria could also enhance gametocyte carriage $[1,2]$. Thus, these variants

\footnotetext{
*Correspondence: Hlamptey@noguchi.ug.edu.gh

1 Immunology Department, Noguchi Memorial Institute for Medical Research, College of Health Sciences, University of Ghana, Legon, Ghana Full list of author information is available at the end of the article
}

may promote sexual differentiation of the asexual parasites [1], as shown in previous in vitro studies in which reticulocyte-rich red cells of sickle cell variants enhanced higher gametocytes formation compared to the normal red cells $[7,8]$. However, an association between $\alpha$-thalassaemia and submicroscopic asexual parasites and gametocytes have, to the best of our knowledge, not been studied. Submicroscopic gametocytes have been shown to be important in malaria transmission $[9,10]$, therefore, knowledge on the effect of $\alpha$-thalassaemia trait on submicroscopic asexual parasite and gametocyte carriage may be important for targeted control. However, studies examining such associations are limited and it is not clear whether these associations differ between different 
demographic groups, since children and pregnant women have been shown to be important gametocyte reservoirs and may impact on transmission [11-13]. This study determined asexual parasite and gametocyte carriage and explored possible association with $\alpha$-thalassaemia among Ghanaian children, adults and pregnant women.

\section{Main text \\ Methods \\ Study population and design}

The study was conducted in Asutsuare and its surrounding villages in the Shai Osudoku District of Ghana. Baseline samples from a longitudinal study conducted from November 2013-September 2014 were used. Ethical approval was given by the Institutional Review Board of Noguchi Memorial Institute for Medical Research, University of Ghana, Legon. The study included three different demographic groups; children (aged 2-15 years), male and non-pregnant female adults (aged 16-65 years), and pregnant women (aged 18-45 years). Informed consent was obtained from all participants and/or their parents/legal guardians prior to their recruitment and inclusion in the study. A detailed description of the study area and population has been presented elsewhere [13].

\section{Sampling techniques and laboratory procedures}

All study participants were screened for their sickle cell status using the sodium metabisulphite method, and this grouped all SS and SC under AS phenotypes. Haemoglobin levels were measured using Hemocue-Hb 201 (Angelholm, Sweden). The ABO blood type was determined using a commercial anti-sera blood grouping kit (Biotec Laboratories Limited, UK).

Blood smears were stained with 10\% Giemsa for detection of both asexual and sexual stage parasites by microscopy under oil immersion (100× magnification). Submicroscopic $P$. falciparum parasites were determined by a previously described nested PCR targeting sequences of the small subunit ribosomal (ssrRNA) $18 \mathrm{~s}$ genes of four Plasmodium species (P. falciparum, $P$. malariae, P. ovale and P. vivax) [14]. RNA was extracted from RNA-later preserved samples that were asexual parasite positive by microscopy and / or PCR using the RNeasy ${ }^{\circledR}$ plus mini kit (Qiagen, Germany). Gametocyte detection was done by real-time (RT) quantitative PCR [15] targeting Pfs 25 transcripts and RNA template for the reaction included 3D7 gametocyte-positive standard RNA generated from parasite culture as previously described [13].

Polymorphisms in the human $\alpha$ globin gene resulting in $\alpha$-thalassaemia, specifically the- $\alpha 3.7$ deletion, was determined by PCR [16]. After genotyping, participants were categorized as normal individuals, heterozygous $\alpha$-thalassaemia or homozygous $\alpha$-thalassaemia based on band size. For single marker association of $\alpha$-thalassaemia alleles with $P$. falciparum infection, it was analyzed under three models of inheritance (dominant, additive and recessive) [17] using logistic regression and adjusting for age as a confounder.

\section{Results}

Submicroscopic asexual parasite and gametocyte prevalence The study population comprised of 463 subjects consisting of children (184), adults (154) and pregnant women (125), of which a total of 167 (36.1\%) of the population were asexual parasite positive. Generally, majority of the parasites detected were submicroscopic. The distribution of asexual $P$. falciparum infections was significantly $\left(\mathrm{P}=0.008, \mathrm{X}^{2}\right.$-test $)$ different among the study groups and majority of these infections were submicroscopic (97\%). The prevalence was highest among the children (49.1\%), compared to adults (28.7\%) and pregnant women $(22.2 \%)$ (Table 1). Only available samples that were positive for asexual parasites by PCR $(n=99)$ were further assessed for gametocytes. From these positives, the gametocyte prevalence was $38.5 \%$ (15/39) among the children, $17.4 \%$ $(4 / 23)$ in the adults and $29.7 \%(11 / 37)$ in the pregnant women. The sickle cell trait distribution among the entire study population for all groups was $4.0 \%$. There were no significant differences in haemoglobin levels, sickle cell trait and blood groups among individuals with parasites and those without parasites $(\mathrm{P}>0.05)$, Table 1 .

\section{The distribution of alpha thalassaemia and association with parasite carriage}

The overall prevalence of heterozygous $\alpha$-thalassaemia was $39.0 \%(176 / 451)$ and $8.2 \%(37 / 451)$ carried the deficient homozygous trait. The distribution of $\alpha$-thalassaemia alleles in the study population did not deviate from Hardy-Weinberg equilibrium $(\mathrm{P}=0.56)$.

Overall, the heterozygous $\alpha$-thalassaemia trait was not associated with asexual parasitaemia $(\mathrm{P}>0.05$, Table 2). However, when the analysis was done with individual groups, the heterozygous trait was associated with reduced risk of asexual parasitaemia in children $(\mathrm{OR}=0.52$; 95\% CI $0.28-0.97 ; \mathrm{P}=0.037)$ but not in adults $(\mathrm{OR}=1.92 ; 95 \%$ CI $0.95-3.89 ; \mathrm{P}=0.066)$ or pregnant women $(\mathrm{OR}=1.7 ; 95 \% \mathrm{CI} 0.79-3.9 ; \mathrm{P}=0.16)$ under the dominant model (Fig. 1a). With the additive and recessive models, heterozygous adults were more likely to carry asexual parasites, compared to the other groups (additive model: $\mathrm{OR}=1.90 ; 95 \% \mathrm{CI} 1.10-3.27 ; \mathrm{P}=0.02$ and recessive model: $\mathrm{OR}=1.10 ; 95 \% \mathrm{CI} 1.05-11.69 ; \mathrm{P}=0.04$ ) (Fig. 1, Top row). There was no significant association between $\alpha$-thalassaemia trait and gametocytaemia in 
Table 1 Demographic and clinical characteristics of study population

\begin{tabular}{|c|c|c|c|c|}
\hline \multirow[t]{2}{*}{ Variables } & \multirow{2}{*}{$\begin{array}{l}\text { Parasite } \\
\text { Negative }(n=296)\end{array}$} & \multirow{2}{*}{$\begin{array}{l}\text { Parasite } \\
\text { Positive }(n=167)\end{array}$} & \multirow[t]{2}{*}{ Total Sample $(n=463)$} & \multirow[t]{2}{*}{$P$ value } \\
\hline & & & & \\
\hline \multicolumn{5}{|l|}{ Groups (\%) } \\
\hline Children & $102(34.5)$ & $82(49.1)$ & $184(39.7)$ & \multirow[t]{3}{*}{0.008} \\
\hline Adults & $106(35.8)$ & $48(28.7)$ & $154(33.3)$ & \\
\hline Pregnant women & $88(29.7)$ & $37(22.2)$ & $125(27.0)$ & \\
\hline \multicolumn{5}{|l|}{ Gender (\%) } \\
\hline Female & $215(72.6)$ & $122(73.1)$ & $337(72.8)$ & \multirow[t]{2}{*}{1.0} \\
\hline Male & $81(27.4)$ & $45(26.9)$ & $126(27.2)$ & \\
\hline \multicolumn{5}{|l|}{ Sickle cell trait (\%) } \\
\hline Negative & $272(95.8)$ & $156(96.3)$ & $428(96.0)$ & \multirow[t]{3}{*}{0.984} \\
\hline Positive & $12(4.2)$ & $6(3.7)$ & $18(4.0)$ & \\
\hline Missing & 12 & 5 & 17 & \\
\hline \multicolumn{5}{|l|}{ Blood group (\%) } \\
\hline A & $57(19.8)$ & $30(18.4)$ & $87(19.3)$ & \multirow[t]{4}{*}{0.517} \\
\hline$A B$ & $14(4.9)$ & $12(7.4)$ & $26(5.8)$ & \\
\hline B & $93(32.3)$ & $45(27.6)$ & $138(30.6)$ & \\
\hline $\mathrm{O}$ & $124(43.1)$ & $76(46.6)$ & $200(44.3)$ & \\
\hline Hemoglobin levels mean, (SD) & $11.1(1.7)$ & $11.0(1.6)$ & $11.1(1.7)$ & 0.329 \\
\hline
\end{tabular}

$P$ values were calculated by Pearson's Chi squared test. $P$ value $<0.05$ is significant

Table 2 Single marker association of a-thalassaemia alleles with $P$. falciparum infection

\begin{tabular}{|c|c|c|c|c|c|c|}
\hline \multirow[t]{2}{*}{ Population } & \multicolumn{2}{|l|}{ Additive model } & \multicolumn{2}{|l|}{ Recessive model } & \multicolumn{2}{|l|}{ Dominant model } \\
\hline & OR $(95 \% \mathrm{Cl})$ & $P$-value & OR $(95 \% \mathrm{Cl})$ & $P$-value & OR $(95 \% \mathrm{Cl})$ & $P$-value \\
\hline Asexual parasites & $1.10(0.81-1.49)$ & 0.53 & $1.41(0.71-2.81)$ & 0.33 & $1.05(0.71-1.56)$ & 0.797 \\
\hline Gametocytes & $0.88(0.4-1.6)$ & 0.67 & $1.42(0.4-4.98)$ & 0.60 & $0.71(0.32-1.58)$ & 0.40 \\
\hline
\end{tabular}

Odds ratio (OR) and $95 \%$ confidence intervals (Cl) were determined using multivariate logistic regression adjusting for age

$\mathrm{P}<0.05$ is significant

pregnant women and children as well as adults with all models (Fig. 1, bottom row).

\section{Discussion}

This study investigated associations between the $\alpha$-thalassaemia trait and $P$. falciparum asexual parasitaemia and gametocytaemia in subjects of different demographic backgrounds in malaria endemic communities in southern Ghana. The overall distribution of heterozygous $\alpha$-thalassaemia observed in this study area was relatively higher $(20 \%$ to $30 \%)$ than observed in other parts of the country $[4,18,19]$. This was probably due to the fact that the community is populated with diverse ethnicity, hence there might have been a lot of inter marriages among the various tribes that might have influenced heterozygosity. Similarly, other studies conducted in other parts of Ghana, and elsewhere have reported a higher prevalence of the heterozygous alpha thalassaemia trait [20-22].
The association of asexual parasite carriage with $\alpha$-thalassaemia trait varied among the groups. This difference in association may be due to possible confounding factors since protection from malaria has been shown to depend on several factors including the host's immune status as well as host genetics [23]. In this study, children with heterozygous $\alpha$-thalassaemia trait had two times reduced risk of harbouring asexual parasites under the dominant model, compared to the normal $\alpha$-thalassaemic carriers after adjusting for age. This finding suggests that the reduced risk of asexual parasite carriage may decrease the likelihood of these children experiencing severe malaria disease. This is in agreement with studies that found heterozygous $\alpha$-thalassaemia being associated with protection from severe disease $[4,6,18]$. Previous studies conducted in other parts of Ghana have shown similar protective effect with respect to reduced asexual parasite density in both heterozygous and homozygous $\alpha$-thalassaemia carriers $[20,24]$. This observation was 


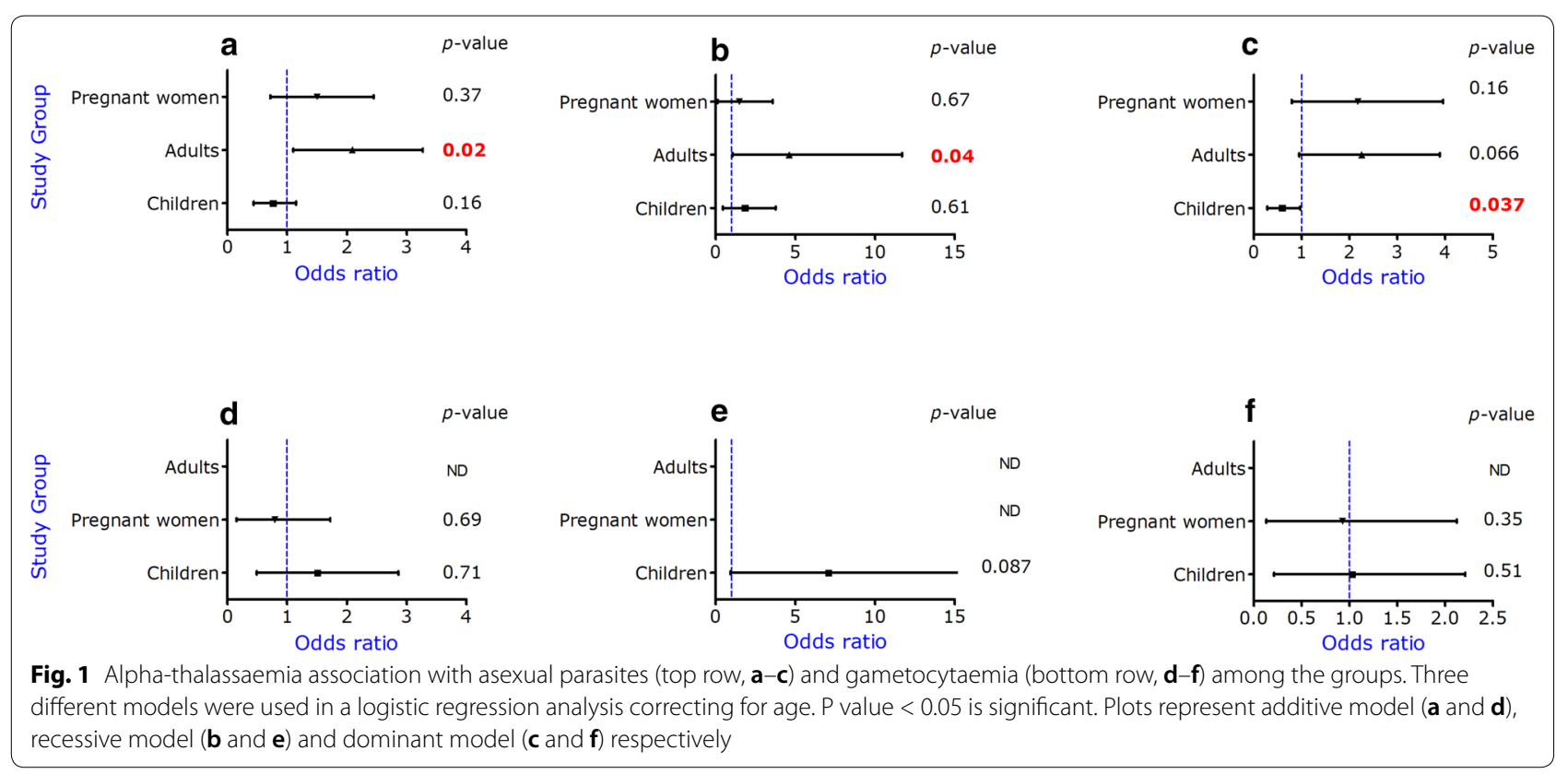

not found in adults, as adults carrying the heterozygous $\alpha$-thalassaemia were found to be more likely to harbour high asexual parasite densities, compared to the other groups. Adults have been shown to have acquired partial immunity against $P$. falciparum infections and are therefore able to clear parasites effectively due to repeated exposure [25]. We can therefore hypothesize that asymptomatic adults seem to have higher parasite threshold due to antidisease immunity, whiles children are less likely to harbour such levels of parasites without succumbing to clinical malaria. The mechanism by which the trait predisposes these adults in this study to asexual parasite carriage is not clear.

Interestingly, some genetic traits such as sickle cell traits with $\mathrm{HbS}$ and $\mathrm{HbC}$ variants that protects against severe malaria have been suggested to promote gametocyte carriage $[1,2]$. However, in this study $\alpha$-thalassaemia trait was not associated with increased risk of gametocyte carriage. Further studies are needed to elucidate the possible mechanisms by which these haemoglobin variants either protect against or confer susceptibility to $P$. falciparum asexual parasitaemia or gametocytaemia.

\section{Conclusion}

The study findings showed that children with heterozygous $\alpha$-thalassaemia trait had reduced risk of asexual parasite carriage under the dominant model. However, there was no association between $\alpha$-thalassaemia trait and risk of gametocyte carriage, perhaps due to limited gametocyte prevalence. Further studies need to be conducted in different transmission areas to ascertain a probable association and mechanisms of $\alpha$-thalassaemia and gametocyte carriage and possibly the infectiousness of these parasites in malaria transmission.

\section{Limitations}

The very low numbers of both asexual parasites and gametocytes is an important limitation of the study and the findings described will need to be confirmed with a larger sample size.

\section{Abbreviations}

RNA: ribonucleic acid; RT-PCR: real time reverse transcription polymerase chain reaction.

\section{Authors' contributions}

$\mathrm{HL}, \mathrm{MFO}, \mathrm{KAK}, \mathrm{IAQ}$ and MA conceived and designed the study, HL, EKD assisted in the laboratory assays and data analysis. BA and KAK assisted in Data management, statistical analysis and data interpretation. HL, MFO, KAK, BA, IAQ and MA wrote the paper. All authors read and approved of the final manuscript.

\section{Author details \\ ${ }^{1}$ Immunology Department, Noguchi Memorial Institute for Medical Research, College of Health Sciences, University of Ghana, Legon, Ghana. ${ }^{2}$ Department of Biological, Environmental and Occupational Health Sciences, School of Pub- lic Health, College of Health Sciences, University of Ghana, Legon, Ghana. ${ }^{3}$ Centre for Medical Parasitology, Department of Immunology and Micro- biology, University of Copenhagen, Copenhagen, Denmark. ${ }^{4}$ Department of Infectious Disease, National University Hospital (Rigshospitalet), Copenha- gen, Denmark.}

\section{Acknowledgements}

We would like to thank parents and study participants from Asutsuare and surrounding villages in Ghana who agreed to be part of this study. Further thanks to technicians in the Immunology Department and Centre for Medical Parasitology, Copenhagen for technical assistance. 


\section{Competing interests}

The authors declare that they have no competing interests.

\section{Availability of data and materials}

The datasets used and /or analysed for this study are included in the article, additional data required are available from the corresponding author on reasonable request.

\section{Consent for publication}

Not applicable.

\section{Ethics approval and consent to participate}

Ethical approval for the study (Approval Number NMIMR-IRB CPN 010 /12) was given by the Institutional Review Board of the Noguchi Memorial Institute for Medical Research, College of Health Sciences, University of Ghana, Legon. The Ethics Review Board of NMIMR holds a United States Government Federal Wide Assurance (FWAA00001824) from the Office for Human Research Protection. All study participants and/or their parents/legal guardians gave written informed consent before enrolment into the study.

\section{Funding}

The study was funded by University of Ghana and DANIDA, under the Human Health Platform of the Building Stronger Universities initiative (BSU-Phase 1).

\section{Publisher's Note}

Springer Nature remains neutral with regard to jurisdictional claims in published maps and institutional affiliations.

Received: 8 January 2019 Accepted: 11 March 2019 Published online: 13 March 2019

\section{References}

1. Gouagna LC, Bancone G, Yao F, Yameogo B, Dabire KR, Costantini C, et al. Genetic variation in human HBB is associated with Plasmodium falciparum transmission. Nat Genet. 2010;42(4):328-31.

2. Lawaly YR, Sakuntabhai A, Marrama L, Konate L, Phimpraphi W, Sokhna $C$, et al. Heritability of the human infectious reservoir of malaria parasites. PLOS ONE. 2010;5(6):e11358.

3. Taylor SM, Parobek CM, Fairhurst RM. Haemoglobinopathies and the clinical epidemiology of malaria: a systematic review and meta-analysis. Lancet Infect Dis. 2012;12:457-68.

4. Mockenhaupt FP, Ehrhardt S, Gellert S, Otchwemah RN, Dietz E, Anemana $\mathrm{SD}$, et al. a+-thalassemia protects African children from severe malaria. Blood. 2004:104(7):2003-6.

5. Williams TN, Maitland K, Bennett S, Ganczakowski M, Peto TEA, Newbold $\mathrm{Cl}$, et al. High incidence of malaria in [alpha]-thalassaemic children. Nature. 1996;383(6600):522-5.

6. Wambua S, Mwangi TW, Kortok M, Uyoga SM, Macharia AW, Mwacharo $\mathrm{JK}$, et al. The effect of a (+)-thalassaemia on the incidence of malaria and other diseases in children living on the coast of Kenya. PLoS Med. 2006;3(5):e158.

7. Trager W, Gill GS, Lawrence C, Nagel RL. Plasmodium falciparum: enhanced Gametocyte Formationin Vitroin reticulocyte-rich blood. Exp Parasitol. 1999;91(2):115-8.

8. Trager W, Gill GS. Enhanced gametocyte formation in young erythrocytes by Plasmodium falciparum in vitro. J Protozool. 1992;39(3):429-32.

9. Schneider P, Bousema JT, Gouagna LC, Otieno S, van de Vegte-Bolmer M, Omar SA, et al. Submicroscopic Plasmodium falciparum gametocyte densities frequently result in mosquito infection. Am J Trop Med Hyg 2007;76(3):470-4

10. Drakeley C, Sutherland C, Bousema JT, Sauerwein RW, Targett GA. The epidemiology of Plasmodium falciparum gametocytes: weapons of mass dispersion. Trends Parasitol. 2006;22(9):424-30.

11. Boudová S, Cohee LM, Kalilani-Phiri L, Thesing PC, Kamiza S, Muehlenbachs A, et al. Pregnant women are a reservoir of malaria transmission in Blantyre, Malawi. Malaria Journal. 2014;13(1):1.

12. Ayanful-Torgby R, Oppong A, Abankwa J, Acquah F, Williamson KC, Amoah LE. Plasmodium falciparum genotype and gametocyte prevalence in children with uncomplicated malaria in coastal Ghana. Malar J. 2016;15(1):592.

13. Lamptey H, Ofori MF, Kusi KA, Adu B, Owusu-Yeboa E, Kyei-Baafour E, et al. The prevalence of submicroscopic Plasmodium falciparum gametocyte carriage and multiplicity of infection in children, pregnant women and adults in a low malaria transmission area in Southern Ghana. Malaria J. 2018;17(1):331

14. Snounou G, Viriyakosol S, Zhu XP, Jarra W, Pinheiro L, Rosario VE. High sensitivity of detection of human malaria parasites by the use of nested polymerase chain reaction. Mol Biochem Parasitol. 1993;61:315-20.

15. Wampfler R, Mwingira F, Javati S, Robinson L, Betuela I, Siba P, et al. Strategies for detection of Plasmodium species gametocytes. PLOS ONE. 2013;8(9):e76316.

16. Liu Y, Old J, Miles K, Fisher C, Weatherall D, Clegg J. Rapid detection of alpha-thalassaemia deletions and alpha-globin gene triplication by multiplex polymerase chain reactions. Br J Haematol. 2000;108(2):295-9.

17. Adu B, Dodoo D, Adukpo S, Hedley PL, Arthur F, Gerds TA, et al. Fc gamma receptor IIIB (FcgammaRIIIB) polymorphisms are associated with clinical malaria in Ghanaian children. PLoS ONE. 2012:7(9):e46197.

18. Ghartey-Kwansah G, Boampong JN, Aboagye B, Afoakwah R, Ameyaw EO, Quashie NB. The prevalence of a-thalassemia and its relation to plasmodium falciparum infection in patients presenting to clinics in two distinct ecological zones in Ghana. Hemoglobin. 2016;40(1):32-7.

19. Opoku-Okrah C, Gordge M, Kweku Nakua E, Abgenyega T, Parry M, Robertson C, et al. An investigation of the protective effect of alpha+thalassaemia against severe Plasmodium falciparum amongst children in Kumasi, Ghana. Int J Lab Hematol. 2014;36(1):62-70.

20. Franklin K, Opoku-Okrah C, Obiri-Danso K, Owiredu W, Annan A. The effect of alpha (+)-Thalassaemia on P. falciparum Malaria parasitaemia in children attending Komfo Anokye Teaching Hospital. Inter J Biomed Lab Sc. 2011;1(1):7-14.

21. Krause MA, Diakite SA, Lopera-Mesa TM, Amaratunga C, Arie T, Traore $\mathrm{K}$, et al. a-Thalassemia impairs the cytoadherence of Plasmodium falciparum-infected erythrocytes. PLoS ONE. 2012;7(5):e37214.

22. Enevold A, Lusingu JP, Mmbando B, Alifrangis $M$, Lemnge MM, Bygbjerg IC, et al. Reduced risk of uncomplicated malaria episodes in children with alpha+-thalassemia in northeastern Tanzania. Am J Trop Med Hyg. 2008;78(5):714-20.

23. Opi DH, Ochola LB, Tendwa M, Siddondo BR, Ocholla H, Fanjo H, et al. Mechanistic studies of the negative epistatic malaria-protective interaction between sickle cell trait and $a+$ thalassemia. EBioMedicine. 2014;1(1):29-36.

24. Pattanapanyasat $\mathrm{K}$, Yongvanitchit $\mathrm{K}$, Tongtawe $\mathrm{P}$, Tachavanich $\mathrm{K}$, Wanachiwanawin W, Fucharoen S, et al. Impairment of Plasmodium falciparum growth in thalassemic red blood cells: further evidence by using biotin labeling and flow cytometry. Blood. 1999;93(9):3116-9.

25. Doolan DL, Dobaño C, Baird JK. Acquired immunity to malaria. Clin Microbiol Rev. 2009:22(1):13-36. 